\title{
Evaluation of Routing Protocols on the Basis of Diverse Network Simulation Area
}

\author{
Meenakshi Sharma \\ M.Tech Scholar \\ SBSSTC, \\ Ferozepur
}

\author{
Navdeep Kaur \\ A.P-ECE \\ SBSSTC, \\ Ferozepur
}

\author{
Gurjeevan Singh \\ DIC-ECE \\ SBSSTC(P.W.), \\ Ferozepur
}

\begin{abstract}
In present scenario, MANETs has gained very much importance and popularity in the research field. The method by which the performance of MANETs can be evaluated is the use of different simulation environments. A MANET is basically collection of distributed mobile nodes where each node whether it is transmitting or receiving data, acts as host as well as router. It is a dynamic wireless network that can be formed without any pre-existing infrastructure. This paper presents the simulation results which describe about the routing protocols on the basis of different performance metrics. AODV performs better than DSDV and ZRP on the basis of parameters like routing overhead, average end to end delay, network overload and packet delivery ratio.
\end{abstract}

\section{General Terms}

Routing, Average End To End Delay, Network Overload, Routing Overhead, Packet Delivery Ratio et. al.

\section{Keywords}

AODV, DSDV, MANET, NS-2, PDR, RREQ, ZRP.

\section{INTRODUCTION}

Mobile Adhoc Networks(MANETs) are the networks in which network topology changes very rapidly and unpredictably. Due to this dynamic topology, the mobile nodes in the network moves to and from a wireless network without any fixed infrastructure[2]. Because of limited transmission area of these nodes, the effective throughput may be less than that of maximum transmission capacity of a node. So, it is required for one mobile node to take assistance of other nodes in forwarding its packets to the desired destination[3]. The major challenges in MANETs are routing of packets with frequent movement of mobile nodes. Also, there are resource issues like power and storage[2]. The vision of adhoc networks is wireless internet, where users can move anywhere, anytime and still remaining connected with rest of the world[4].

\section{ROUTING IN MANETS}

In MANETs, communication between mobile nodes always requires routing over multi-hop paths. Since, no infrastructure exists and node mobility may cause frequent link failure, it is a great challenge to design an effective and adaptive routing protocols. Some restrictions are also considered such as bandwidth and limited power[5]. MANETs are capable of handling topology changes and malfunctions in nodes through network configurations[6]. MANETs use different routing protocols according to the requirement which are classified according to several criteria, reflecting fundamental design and implementation choices[7].
- Table driven

- $\quad$ Demand driven(Source initiated)

\subsection{Table driven protocols}

These are the protocols which maintain consistent and up to date routing information about each node in the network. These type of protocols require each node to store their routing information and when there is change in network topology, updating the information throughout the network .e.g. DSDV(Destination Sequenced Distance vector), WRP(Wireless Routing Protocol ), OLSR(Optimized link State Routing) etc[7].

\subsection{Demand Driven Protocols}

In these type of protocols, the routes are created when required. When source wants to send to destination, it appeals to the route discovery mechanisms to find the path to the destinations. The route remains valid till the destination is reachable or until the route is no longer needed. e.g. AODV(Adhoc on-demand distance vector), DSR(Dynamic source Routing), TORA(Temporally ordered routing algorithm) etc[7].

To increase the scalability and efficiency of routing protocols third type of routing protocols are introduced which are basically the combination of characteristics of both reactive and proactive routing protocols and are called Hybrid Routing Protocols. These type of protocols are generally based on the concept of zones i.e. the whole network is divided into different number of zones. e.g. ZRP, ZHLS,SLURP[8].

\section{BRIEF DESCRIPTION OF AODV, DSDV AND ZRP}

In this paper, the comparison of above three types of protocols is done by taking one from each type i.e. AODV as reactive routing protocol, DSDV as proactive routing protocol and ZRP as hybrid routing protocol.

\subsection{Adhoc On-demand Distance Vector}

With AODV, a source node that wants to send message to a destination for which it doesn't have a route, broadcasts an RREQ packet across the network. All the nodes receiving this packet update their information for the source node. In AODV, each node maintains only the next hop's address in a routing table and these routing tables are updated all the way along the RREQ propagation path. The RREQ contains the source node's address, broadcast ID and current sequence number as well as the destination node's most recent sequence number

MANETs routing protocols can be categorized as: 


\subsection{Destination Sequenced Distance Vector}

DSDV is basically expansion of traditional distance vector routing protocols. In this routing protocol, routing messages are exchanged among mobile nodes that are within the range of one another. A packet for which the route to its destination is not known is cached while the routing queries are sent out. The packets are cached until rout replies are received from the destination[10].

\subsection{Zone Routing Protocol}

ZRP is a hybrid of proactive and reactive routing protocols. Since the advantage of either of the approaches depends on the characteristics of the network like degree of mobility, it could be beneficial to combine them. This protocols broadcasts a RREQ to all border nodes within the routing zone, which forwards the request if the destination node is not found within their routing zone[10].

\section{SIMULATION SETUP}

The simulation is performed using NS-2 simulator. NS-2 is chosen because it supports large number of routing protocols and offers easy graphical interface. The whole simulation is performed using constant number of nodes and by having different scenarios of $5000 \mathrm{~m} * 5000 \mathrm{~m}, 6000 \mathrm{~m} * 6000 \mathrm{~m}$, $7000 \mathrm{~m} * 7000 \mathrm{~m}$ and $8000 \mathrm{~m} * 8000 \mathrm{~m}[11]$.

Table1. Simulation set up used

\begin{tabular}{|l|l|}
\hline Protocols & AODV, DSDV and ZRP \\
\hline Simulator & NS- 2.34 \\
\hline Nodes & 150 \\
\hline Simulation Area & $\begin{array}{l}5000 \mathrm{~m} * 5000 \mathrm{~m}, 6000 \mathrm{~m} * 6000 \mathrm{~m}, 7000 \mathrm{~m} \\
* 7000 \mathrm{~m} \text { and } 8000 \mathrm{~m} * 8000 \mathrm{~m}\end{array}$ \\
\hline Packet Size & $1 \mathrm{kbps}$ \\
\hline Simulation Time & $1000 \mathrm{sec}$. \\
\hline Traffic Type & High quality GSM voice \\
\hline
\end{tabular}

\section{PERFORMANCE METRICS}

\subsection{Routing Overhead}

Routing Overhead is the total number of control or routing (RTR) packets generated by routing protocols during the simulation. All the packets sent or forwarded at network layer is considered routing overhead[13]. On the whole, they are number of extra packets transmitted per data packet delivered at the destination[12]. Lesser value of routing overhead provides better results.

\subsection{Average End to End Delay}

This includes all possible delays caused by buffering during route discovery latency, queuing at the interface queue, retransmission delays at the MAC, and propagation and transfer times[1].

\subsection{Network Overload}

In wireless mobile adhoc networks, where there is congestion in the network due to outsized number of nodes which are sending and receiving data beyond the limit of its communication area, this is known as network overload.

\subsection{Packet Delivery Ratio}

It is ratio of number of packets received at the destination nodes to the number of packets sent from the source node. Higher value of PDR provides better results[13].

\section{RESULTS AND OBSERVATIONS}

This section provides the simulation results in order to choose the best routing protocol among AODV,DSDV and ZRP by varying the simulation area from $5000 \mathrm{~m} * 5000 \mathrm{~m}$ to $8000 \mathrm{~m} * 8000 \mathrm{~m}$ and denoting these simulation areas by different scenarios viz. S1 for $5000 \mathrm{~m} * 5000 \mathrm{~m}, \quad \mathrm{~S} 2$ for $6000 \mathrm{~m}^{*} 6000 \mathrm{~m}, \quad \mathrm{~S} 3$ for $7000 \mathrm{~m}^{*} 7000 \mathrm{~m}$ and $\mathrm{S} 4$ for $8000 \mathrm{~m} * 8000 \mathrm{~m}[14]$.

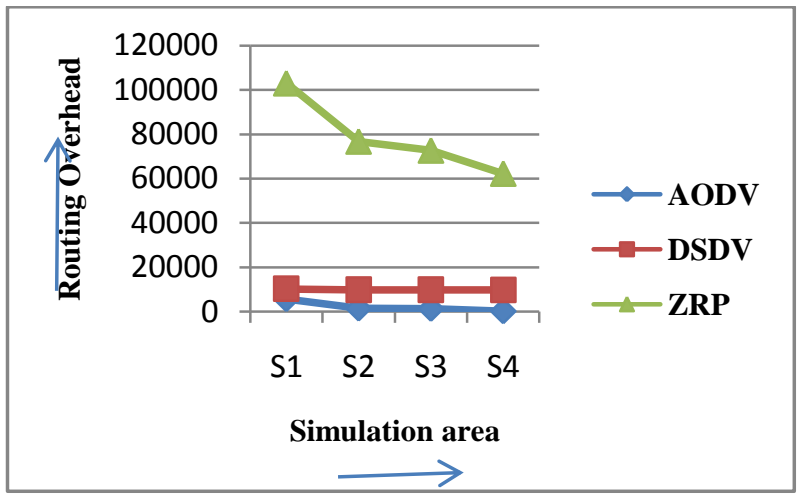

Fig1:Routing overhead for AODV,DSDV and ZRP for different scenarios

In figure 1,AODV offers least routing overhead as compared to DSDV and ZRP .ZRP provides maximum routing overhead. The condition for a routing protocol to have best performance is that routing overhead should be minimum. Here AODV fulfills this condition and is counted better among other routing protocols.

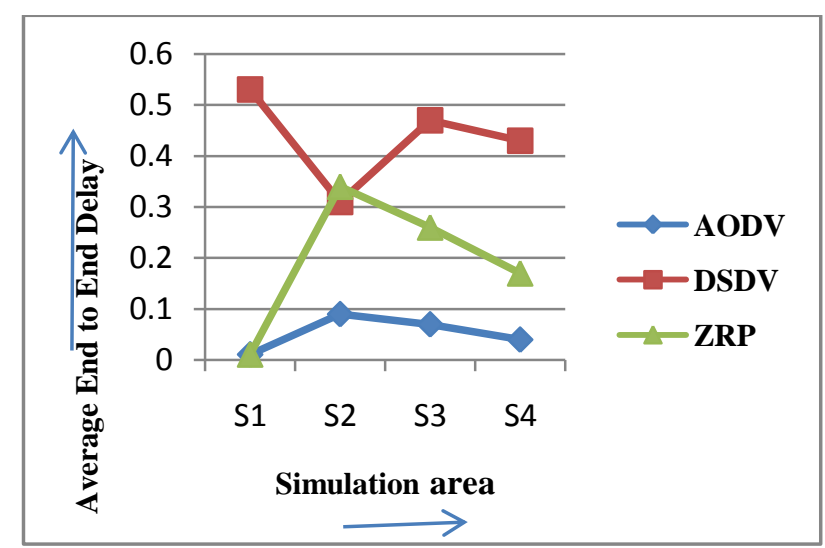

Fig2: Average End to End Delay for AODV,DSDV and ZRP for different scenarios

In figure2, Average end to end delay is minimum for AODV and is maximum for DSDV .Among all these protocols the protocol which favors the condition for best protocol is AODV. 


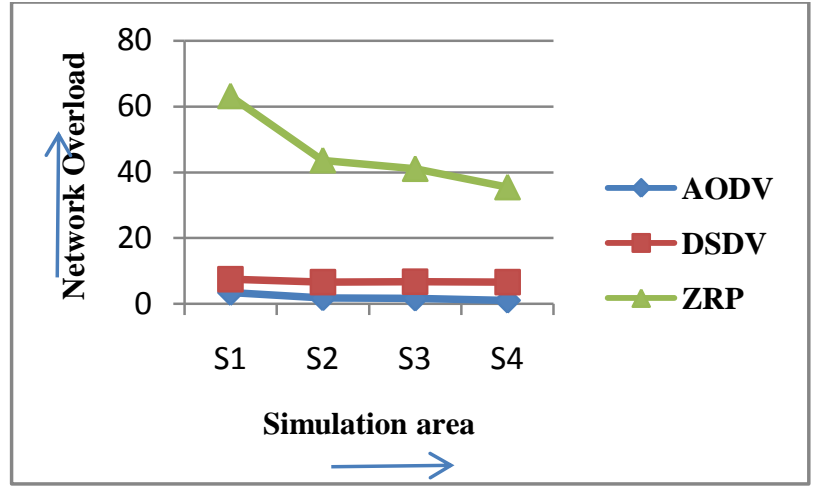

Fig3: Network overload for AODV,DSDV and ZRP for different scenarios

In figure3, Network overload is minimum for AODV and maximum for ZRP. According to the above said definition of network overload it should be minimum to have better results. So, here again AODV performs better against DSDV and ZRP.

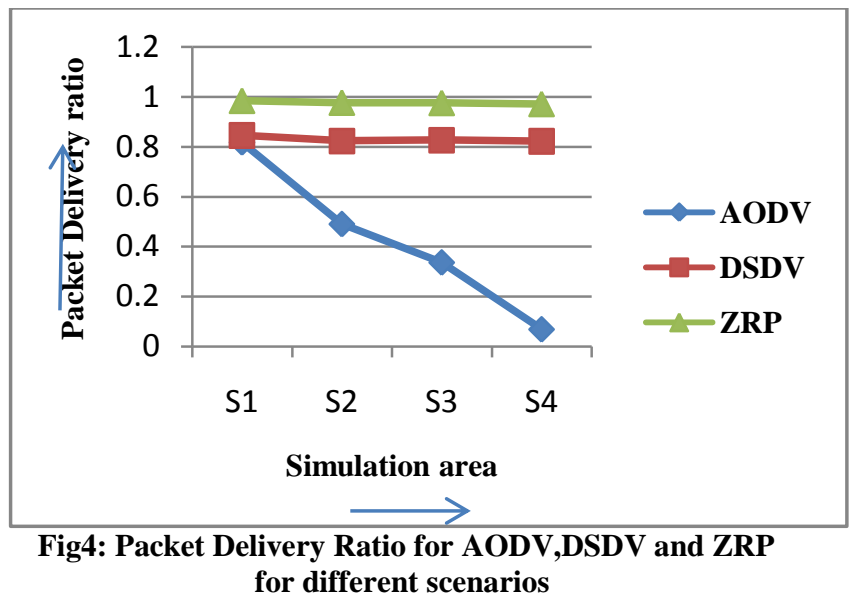

In figure 4, ZRP performs better because it provides maximum packet delivery ratio as compared to AODV and DSDV.

\section{CONCLUSION}

In this research paper, the overall simulation is based on three routing protocols of MANETs by having constant number of nodes and using distinct performance parameters like routing overhead, Average End to End delay, Network Overload and Packet Delivery ratio. The first three parameters discussed are in favor of AODV and last one is in the favor of ZRP. So, the analysis concludes that AODV is counted better routing protocol from DSDV and ZRP on the basis of the performance metrics used.

For future work, the simulation area can be extended and also the number of nodes can be increased. Also, the other simulators like MATLAB, opnet, optisim etc can also be used.

\section{REFERENCES}

[1] Gupta, Anuj K., Harsh Sadawarti, and Anil K. Verma.2010. Performance analysis of AODV, DSR \& TORA routing protocols. IACSIT international journal of Engineering and Technology, 226-231.

[2] Qasim, Nadia, Fatin Said, and Hamid Aghvami.2008. Mobile Ad hoc Networks simulations using Routing protocols for Performance comparisons. Proceedings of the World Congress on Engineering. Vol. 1.

[3] Singh, Rajeshwar, Dharmendra K. Singh, and Lalan Kumar. 2011Performance Evaluation of DSR and DSDV Routing Protocols for Wireless Ad Hoc Networks. Int. J. Advanced Networking and Applications, 732-737.

[4] Sesay, Samba, Zongkai Yang, and Jianhua He.2004. A survey on mobile ad hoc wireless network. Information Technology Journal, 168-175.

[5] Rahman, Abdul Hadi Abd, and Zuriati Ahmad Zukarnain. 2009.Performance comparison of AODV, DSDV and I-DSDV routing protocols in mobile ad hoc networks. European Journal of Scientific Research,566576.

[6] Nand, Parma, and Dr SC Sharma.2011.Performance study of broadcast based mobile adhoc routing protocols AODV, DSR and DYMO. International Journal of Security and Its Applications, 53-64.

[7] Jayakumar, Geetha, and G. Gopinath.2007.Ad hoc mobile wireless networks routing protocols-a review. Journal of Computer science. 574.

[8] Singh, Abhishek, and Anil K. Verma.2013.SIMULATION AND ANALYSIS OF AODV, DSDV, ZRP IN VANET. International Journal in Foundations of Computer Science \& Technology.

[9] Milanovic, Nikola, et al.2004 .Routing and security in mobile ad hoc networks.Computer, 61-65.

[10] Pahuja, Poonam, Sanjay Pahuja, and Tarun Shrimali.2012 Analysis and Simulations of Routing Protocols with Different Load Conditions of MANETs. International Journal .

[11] Kumar, Lovekesh. Scalability Performance of AODV, TORA and OLSR with Reference to Variable Network Size.

[12] Verma, Neha, Vijay Joshi, and Arun Kumar. 2012.Performance Evaluation and Analysis of Reactive Routing Protocols in MANET. International Journal of Computer Applications.

[13] Khiavi, Mina Vajed, Shahram Jamali, and Sajjad Jahanbakhsh Gudakahriz.2012 .Performance Comparison of AODV, DSDV, DSR and TORA Routing Protocols in MANETs. International Research Journal of Applied and Basic Sciences 3.7 1429-1436.

[14] Usop, Nor Surayati Mohamad, Azizol Abdullah, and Ahmad Faisal Amri Abidin. 2009.Performance evaluation of AODV, DSDV \& DSR routing protocol in grid environment. IJCSNS International Journal of Computer Science and Network Security, 261-268.

[15] Sharma, Vishal, et al.2012 .Performance evaluation of reactive routing protocols in MANET networks using GSM based voice traffic applications. OptikInternational Journal for Light and Electron Optics. 